\title{
Mass media influence and risk of developing eating disorders in female students from Lima, Peru
}

\author{
Yessenia Lazo Montoya, B.S. ${ }^{a}$, Alejandra Quenaya, B.S. ${ }^{a}$, and Percy Mayta-Tristán, M.D. ${ }^{b}$
}

\begin{abstract}
Introduction. Eating disorders(EDs) are a public health problem, and their relationship to mass media is still controversial.

Objective. Toassess whether thereis an association between models of body image shown in mass media and the risk of developing EDs among female adolescent students from Lima, Peru.

Methodology. Cross-sectional study conducted in three schools located in the district of La Victoria, Lima, Peru. The risk of developing EDs was measured using the Eating Attitudes Test-26 (EAT-26), while mass media influence was measured using the Sociocultural Attitudes Towards Appearance Questionnaire-3 (SATAQ-3), which was categorized into tertiles both in the overall score and its subscales (information, pressure, general internalization, and athleticinternalization). Adjusted prevalence ratios (aPR) for EDs were estimated.

Results. Four hundred and eighty-three students were included, their median age was $14 \pm 3$ years old. A risk of developing an ED was observed in $13.9 \%$ of them. Students who are more influenced by mass media (upper tertile of the SATAQ-3) have a higher probability of having a risk of developinganED(aPR: 4.24;95\% confidence interval [CI]: 2.10-8.56), as well as those who have a greater access to information (PR: $1.89 ; 95 \% \mathrm{CI}$ : 1.09-3.25), suffer more pressure(PR: $4.97 ; 95 \% \mathrm{CI}$ : 2.31-10.69), show a greater general internalization (PR: 5.00; 95\% CI: 2.39-10.43), and show a greater level of athletic internalization (PR: 4.35; 95\% CI: 2.19-8-66).

Conclusion.The greater the influence of mass media, the greater the probability of having a risk of developing an ED among female students from Lima, Peru.

Key words: eating disorders, mass media, students, adolescent, Peru.
\end{abstract}

b. School of Medicine. Universidad Peruana de Ciencias Aplicadas, Lima, Peru.

E-mail Address:

Yessenia Lazo Montoya, B.S.: yessenia.lazo. montoya@gmail.com

Funding:

None.

Conflict of interest: None.

Received: 5-12-2015

Accepted: 7-30-2015 http:/ /dx.doi.org/10.5546/aap.2015.eng.519

\section{INTRODUCTION}

Eating disorders (EDs) are the third most common chronic disease among adolescent girls in industrialized countries. ${ }^{1}$ ED prevalence has increased and has been reported to be between $0.5 \%$ and $1 \%$ over the past decades. ${ }^{2}$

In Peru, the number of new cases registered by facilities that report to the Ministry of Health between 1998 and 2008 has increased eightfold. ${ }^{3}$ In addition, in Lima Metropolitana, it has been estimated that $16.4 \%$ of adolescent female students had a risk of developing an ED. ${ }^{4}$ Identifying the population at risk would allow to make an early diagnosis, which is critical during treatment to prevent these disorders from becoming chronic. ${ }^{5}$ In this regard, knowing these factors, as well as treatment for EDs, and generating the need to implement preventive strategies aimed at stopping their dissemination should be priority items in the agenda of the health sector.

ED pathogenesis has still not been fully understood because of its multiples causes. ${ }^{6}$ Associated factors include, among others, depression, anxiety and body image dissatisfaction. The latter is the most common factor. Such dissatisfaction is the result of a gap generated between a real body image and an ideal body image, caused by the internalization of an ideal body culturally proposed to teenagers by mass media (MM) and social standards, e.g., popularity, fashion, sexual appeal, and rejection of obesity. This leads adolescent girls to focus on external appearance and the resulting social success. ${ }^{1,8,9}$ For all these reasons, it is important to identify the factors that influence EDs and therefore help to prevent them.

MM may have a strong influence on the initiation and occurrence of EDs, ${ }^{1}$ because MM usually show models of thinness that may be associated with beauty and therefore convey a wrong idea regarding body image. ${ }^{10-12}$ As a result, MM may send messages that are harmful for the mental health of the youth population, 
especially in relation to the risk of developing an ED. ${ }^{13,14}$

Adolescent girls are continuously exposed to such body shape models in television, magazines and movies because of the relevance they acquire for these girls. ${ }^{1}$ For this reason, the objective of this study is to assess whether there is an association between body image models shown in MM and the risk of developing an ED among adolescent girls from Lima, Peru.

\section{METHODOLOGY \\ Study design}

During the third trimester of 2014, an analytical, cross-sectional study was conducted in three schools located in the district of La Victoria (Lima, Peru).

\section{Population and sample}

Adolescent female students aged 12 to 17 years old from a private and two public schools, who were attending first through fifth year of secondary education in 2014 were included. Pregnant girls and those who did not obtain their parents' authorization to participate in the study were excluded.

The sample size was estimated using the PASS v13.0 software for Poisson regression, considering a binomial distribution, ${ }^{15}$ with a power of $90 \%$, a confidence level of $95 \%$, an expected prevalence ratio of 1.5 , an ED prevalence of $24 \%$ obtained from a pilot study, ${ }^{16}$ and an R2 of 0.3 . As per the estimation, the minimum number necessary was 449 female students. Considering potential incorrectly filled cards, lack of consent from parents and school size, it was decided to conduct a census.

\section{Measurements}

The risk of developing an ED was measured using the Spanish-language version of the Eating Attitudes Test-26 (EAT-26), ${ }^{17}$ which has been validated in Colombia. This instrument is made up of 26 items with six answer options ("never", "rarely", "sometimes", "often", "usually" or "always"). The first three options score zero; the fourth option, one; the fifth option, two; and the sixth option, three; item 25 is scored inversely. A score at or above 20 is considered a risk of developing an ED. ${ }^{18}$ Cronbach's alpha for this study was established at 0.92 .

MM influence was measured using the Spanish-language version of the Sociocultural Attitudes Towards Appearance Scale-3 (SATAQ-3), ${ }^{19}$ which has been validated in
Spain. ${ }^{20}$ It is made up of 30 items scored using a 1 to 5 Likert scale, which are divided into four subscales: (1) information, that measures general knowledge on Western beauty ideals; (2) general internalization, that measures internalization of body ideal; both of these contain 9 items; (3) pressure, that measures pressure exercised by beauty ideals depicted in multiple media, which contains 7 items; (4) athletic internalization, that measures acceptance of an athletic appearance ideal, which is made up of 5 items. The overall score is 30 to 150 points; a higher score indicates a higher MM influence.

The SATAQ-3 and its subscales have no cutoff points; therefore, tertiles were generated and the upper and middle tertiles were compared to the lower tertile (smaller influence).

In addition, age, type of school (public/ private), year in school, self-reported weight and height were assessed, and body mass index (BMI) was estimated.

TABLE 1.General characteristics of female students

\begin{tabular}{lrl}
\hline Characteristics & $\mathbf{n}$ & $(\mathbf{\%})^{*}$ \\
\hline School year & 122 & $(25.3)$ \\
$\quad$ First & 106 & $(22.0)$ \\
$\quad$ Second & 66 & $(13.7)$ \\
$\quad$ Third & 74 & $(15.3)$ \\
$\quad$ Fourth & 115 & $(23.8)$ \\
$\quad$ Fifth & & \\
School & 219 & $(45.3)$ \\
$\quad$ Public & 264 & $(54.7)$ \\
$\quad$ Private & 14 & $(3.0)$ \\
Age (years) & 157 & $(9.0)$ \\
Height (cm)* & 52.3 & $(11.0)$ \\
Weight (kg) & 21.4 & $(3.9)$ \\
BMI* & & \\
ED & 67 & $(13.9)$ \\
$\quad$ Yes & 416 & $(86.1)$ \\
$\quad$ No & & \\
SATAQ-3 & 86 & $(28.0)$ \\
$\quad$ Overall* & 28 & $(7.0)$ \\
Information* & 18 & $(10.0)$ \\
Pressure* & 25 & $(9.0)$ \\
General internalization* & 14 & $(6.0)$ \\
$\quad$ Athletic internalization* & & \\
\hline
\end{tabular}

*Median and (interquartile range).

BMI: body mass index.

ED: eating disorder.

SATAQ-3: Sociocultural Attitudes Towards Appearance Questionnaire-3. 


\section{Procedures and ethical aspects}

The study was approved by the Ethics Committee of Universidad Peruana de Ciencias Aplicadas and was authorized by the deans of the three schools, which were selected by convenience based the facilities provided. Each minor participated once their informed assent and an informed consent were obtained. Then students completed the surveys anonymously. Overall results were returned to each school through their Departments of Psychology.

\section{Data analysis}

A double-entry database was generated, and then analyzed using the STATA software, v13.0. Numerical outcome measures were first verified for "non normality" using the ShapiroWilk test and then expressed as median values and interquartile ranges (IQR) and subsequently categorized into tertiles. Categorical outcome measures were expressed in percentages. The prevalence of risk of developing an ED was estimated, and the association was assessed using a ${ }^{2}$ test and a Wilcoxon rank-sum test, as applicable. In order to assess the extent of the association between the risk of developing an ED and the SATAQ-3, both overall and its four subscales, crude and adjusted prevalence ratios and their 95\% confidence intervals (CIs) were estimated using Poisson regression models with a robust variance. Adjusted models for each exposure (SATAQ-3 and its subscales) included the following variables: age, weight, height, and type of school. A $p$ value $<0.05$ was considered significant.

\section{RESULTS}

Out of a total of 700 female students from three schools located in Lima, 483 were included in the analysis (Figure 1). Their median age was 14 years old (IQR: 3 ) and their median BMI was 21.4 (IQR: 3.9 ). Besides, $54.7 \%$ of participants attended a private school, and $47.2 \%$ were in the first and second years of secondary education. Their median SATAQ-3 score was 86, and their median score in the information subscale was 28 . For the pressure subscale, their median score was 18; for the general internalization subscale, 25; and for

FIGURE 1. General flow of how participants included in the analysis were selected

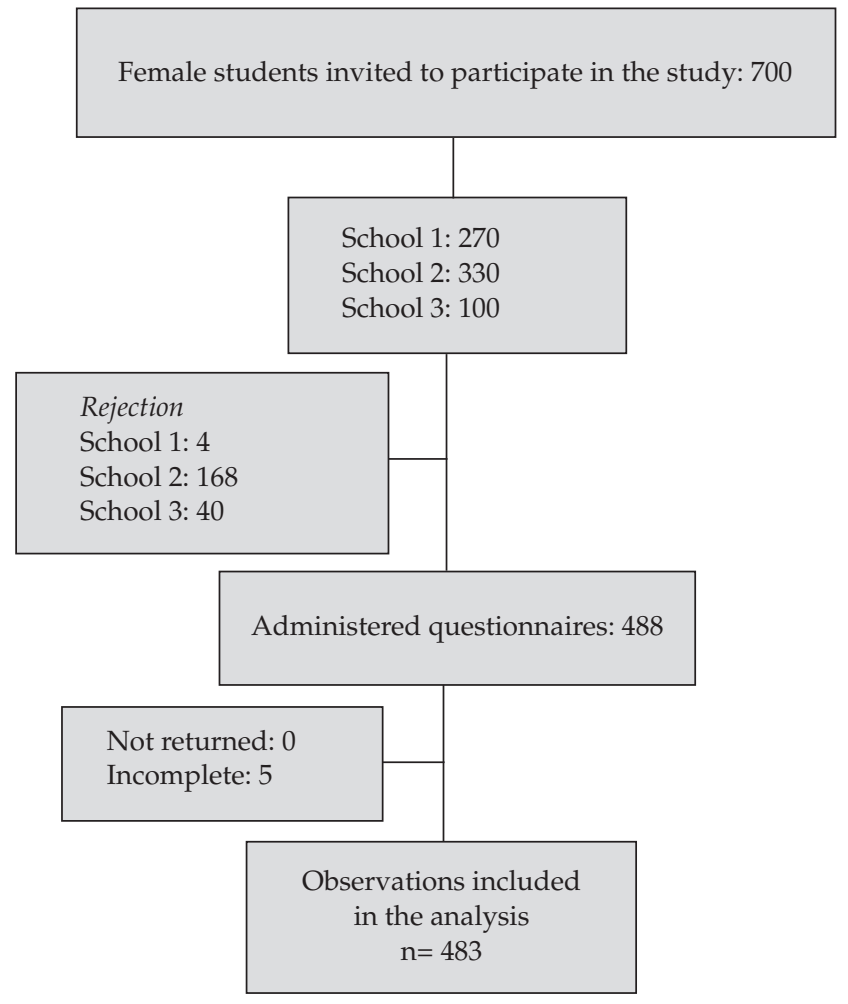


the athletic internalization subscale, 14. Cronbach's alpha was established at 0.73 for the SATAQ-3 and at 0.92 for the EAT-26.

A risk of developing an ED was observed in $13.9 \%$ of female students. No association between school year, type of school, age and BMI and the risk of developing an ED was observed $(p>0.05$; Table 2).

An association was noticed between SATAQ-3 scores, both overall and subscale scores, and the risk of developing an ED, and this is maintained after making adjustments for other outcome measures (Table 3). In addition, it was observed that the risk of developing an ED is higher among participants who are more influenced by MM (PR: 4.24; 95\% CI: 2.10-8.56), those who have a greater access to information (PR: 1.89, 95\% CI: 1.09-3.25), suffer more pressure (PR: 4.97; 95\% CI: 2.31-10.67), have a greater general internalization (PR: 5.0; 95\% CI: 2.39-10.43), and showed a greater level of athletic internalization (PR: 4.35; 95\% CI: 2.198-66).

\section{DISCUSSION}

We observed that, the greater the influence of mass media on the body image of assessed

TABLE 2. Association between school characteristics and risk of developing an eating disorder in Lima, 2014

\begin{tabular}{|c|c|c|c|c|c|}
\hline \multirow[t]{2}{*}{ Characteristics } & \multicolumn{2}{|c|}{$\operatorname{ED}(n=67)$} & \multicolumn{2}{|c|}{ No ED $(n=416)$} & \multirow[t]{2}{*}{$\mathbf{P}$} \\
\hline & $\mathrm{n}$ & $(\%)$ & n & $(\%)$ & \\
\hline \multicolumn{6}{|l|}{ School year* } \\
\hline First & 17 & (13.9) & 105 & $(86.1)$ & 0.522 \\
\hline Second & 11 & (10.4) & 95 & $(89.6)$ & \\
\hline Third & 13 & (19.7) & 53 & $(80.3)$ & \\
\hline Fourth & 9 & (12.1) & 65 & $(87.8)$ & \\
\hline Fifth & 17 & (14.8) & 98 & $(85.2)$ & \\
\hline \multicolumn{6}{|l|}{ School $^{*}$} \\
\hline Public & 32 & $(14.6)$ & 187 & $(85.4)$ & 0.668 \\
\hline Private & 35 & (13.3) & 229 & $(86.7)$ & \\
\hline Age (years) ${ }^{* *}$ & 14 & $(3.0)$ & 14 & (3.0) & 0.2324 \\
\hline Height $(\mathrm{cm})^{* *}$ & 160 & $(8.0)$ & 157 & (9.0) & 0.0251 \\
\hline Weight $(\mathrm{kg})^{* *}$ & 55 & $(10.0)$ & 52 & $(11.0)$ & 0.0241 \\
\hline $\mathrm{BMI}^{* *}$ & 21.88 & (3.6) & 21.24 & $(3.9)$ & 0.2046 \\
\hline \multicolumn{6}{|c|}{ Mass media influence (SATAQ- 3 overall score) ${ }^{*} \dagger$} \\
\hline Small influence ( $<78$ points) & 9 & $(5.3)$ & 162 & $(94.7)$ & $<0.001$ \\
\hline Regular influence (78 to 94 points) & 22 & $(14.2)$ & 133 & $(85.8)$ & \\
\hline Big influence ( $>94$ points) & 36 & $(22.9)$ & 121 & $(77.1)$ & \\
\hline \multicolumn{6}{|l|}{ Information ${ }^{*}+$} \\
\hline Low $(<27$ points $)$ & 18 & $(10.0)$ & 163 & $(90.1)$ & 0.034 \\
\hline Middle (27 to 30 points) & 18 & $(12.6)$ & 125 & $(87.4)$ & \\
\hline High (>30 points) & 31 & (19.5) & 128 & $(80.5)$ & \\
\hline \multicolumn{6}{|l|}{ Pressure $^{*}+$} \\
\hline Low $(<16$ points $)$ & 8 & $(4.7)$ & 163 & $(95.3)$ & $<0.001$ \\
\hline Middle (16 to 21 points) & 25 & $(15.4)$ & 137 & $(84.6)$ & \\
\hline High (>21 points) & 34 & $(22.7)$ & 116 & $(77.3)$ & \\
\hline \multicolumn{6}{|l|}{ General internalization*† } \\
\hline Low (<23 points) & 8 & $(4.8)$ & 160 & $(95.2)$ & $<0.001$ \\
\hline Middle (23 to 28 points) & 21 & (13.3) & 137 & $(86.7)$ & \\
\hline High ( $>28$ points) & 38 & $(24.2)$ & 119 & $(75.8)$ & \\
\hline \multicolumn{6}{|l|}{ Athletic internalization*† } \\
\hline Low ( $<13$ points) & 10 & $(5.0)$ & 189 & $(95.0)$ & $<0.001$ \\
\hline Middle (13 to 16 points) & 29 & $(18.0)$ & 132 & $(82.0)$ & \\
\hline High (>16 points) & 28 & $(22.8)$ & 95 & $(77.2)$ & \\
\hline
\end{tabular}


female students, the greater the probability of having a risk of developing an ED, an aspect that corroborates what has been previously stated: the ideal of thinness shown by MM and sociocultural pressure are related to higher rates of EDs among women because they produce harmful effects on body ideal. ${ }^{10}$

In addition, MM influence may lead adolescent girls to internalize ideals imposed by society as desirable, to recognize them as social standards and therefore make them feel dissatisfied because they do not have an ideal body. ${ }^{21-23}$ This results in a gap between what is ideal and how individuals see themselves, and this is what determines their level of satisfaction..$^{24}$ In addition, different studies have shown that MM usually disseminate misconceptions about body ideals, ${ }^{25,26}$ because they convey an excessive pressure on girls to be thin, leading to a greater risk of developing an ED.

SATAQ-3 measures the influence of MM by asking about television, movies and magazines, but leaves out advertisements and the Internet. However, it cannot be denied that the last two also have a great influence on adolescent girls. Over the last years, the Internet -and especially social networks- have played an important role in communication and access to information worldwide. Recent studies have evidenced that social networks, specifically Facebook, increase "appearance exposure", which is positively correlated with increased body image disturbance and, therefore, EDs. ${ }^{27}$

In addition, the level of urbanization has a significant impact on the incidence of this type of disorder. However, social class, school status and the year attended in school did not appear to be related to a higher risk of developing an ED. ${ }^{28}$ Additional studies are necessary to explain the association between ED influence and nutritional status, body image and socioeconomic level.

It is known that a higher BMI results in a higher risk of developing an ED;29,30 however, in our study, data did not evidence such association. Although self-reported weight is correlated to actual weight, ${ }^{31}$ this may have been the reason why no association was observed between BMI and EDs, as observed in previous studies. ${ }^{29,30}$

There are other factors associated with the risk of developing an ED that were not measured, for example, depression and self-esteem, ${ }^{4,14}$ family pressure, weight-related bullying, among others, ${ }^{24}$ which may affect the association between EDs

TABLE 3. Association between mass media influence and risk of eating disorders in female students from Lima, Peru, 2014 $(n=483)^{*}$

\begin{tabular}{|c|c|c|c|c|c|c|}
\hline \multirow{2}{*}{$\begin{array}{l}\text { Mass media } \\
\text { influence }\end{array}$} & \multicolumn{3}{|c|}{ Crude model } & \multicolumn{3}{|c|}{ Adjusted model* } \\
\hline & PR & $(95 \% \mathrm{CI})$ & $\mathbf{P}$ & aPR & $(95 \% \mathrm{CI})$ & $p$ \\
\hline \multicolumn{7}{|l|}{ Overall SATAQ-3 } \\
\hline Small influence & 1.00 & Reference & 1.00 & Reference & & \\
\hline Regular influence & 2.70 & (1.28 to 5.68$)$ & 0.009 & 2.71 & (1.28 to 5.72$)$ & 0.009 \\
\hline Big influence & 4.36 & (2.17 to 8.76$)$ & $<0.001$ & 4.24 & (2.10 to 8.56$)$ & $<0.001$ \\
\hline \multicolumn{7}{|l|}{ Information $* *$} \\
\hline Low (<27 points) & 1.00 & Reference & 1.00 & Reference & & \\
\hline Middle (27 to 30 points) & 1.27 & (0.68 to 2.34$)$ & 0.453 & 1.22 & (0.66 to 2.24$)$ & 0.529 \\
\hline High (>30 points) & 1.96 & (1.14 to 3.37$)$ & 0.015 & 1.89 & (1.09 to 3.25$)$ & 0.023 \\
\hline \multicolumn{7}{|l|}{ Pressure $^{* *}$} \\
\hline Low (<16 points) & 1.00 & Reference & 1.00 & Reference & & \\
\hline Middle (16 to 21 points) & 3.30 & (1.53 to 7.11$)$ & 0.002 & 3.20 & (1.48 to 6.88$)$ & 0.003 \\
\hline High (>21 points) & 4.84 & (2.31 to 10.15$)$ & $<0.001$ & 4.97 & (2.31 to 10.67$)$ & $<0.001$ \\
\hline \multicolumn{7}{|l|}{ General internalization** } \\
\hline Low (<23 points) & 1.00 & Reference & 1.00 & Reference & & \\
\hline Middle (23 to 28 points) & 2.79 & $(1.27$ to 6.12$)$ & 0.010 & 2.77 & $(1.26$ to 6.10$)$ & 0.012 \\
\hline High (>28 points) & 5.08 & (2.45 to 10.56$)$ & $<0.001$ & 5.00 & (2.39 to 10.43$)$ & $<0.001$ \\
\hline \multicolumn{7}{|l|}{ Athletic internalization ${ }^{* *}$} \\
\hline Low (<13 points) & 1.00 & Reference & 1.00 & Reference & & \\
\hline Middle (13 to 16 points) & 3.58 & (1.80 to 7.14$)$ & $<0.001$ & 3.51 & (1.76 to 7.01$)$ & $<0.001$ \\
\hline High (>16 points) & 4.53 & (2.28 to 9.00$)$ & $<0.001$ & 4.35 & (2.19 to 8.66$)$ & $<0.001$ \\
\hline
\end{tabular}

* Adjusted by age, weight, height, type of school.

** Tertiles.

SATAQ-3: Sociocultural Attitudes Towards Appearance Questionnaire-3.

PR: prevalence ratios; aPR: adjusted prevalence ratios. 
and MM influence and that may reduce the strong association identified.

The EAT-26 is a summary version of the EAT40 and is used to measure the risk of developing an ED through the detection of typical symptoms and problems in non-clinical samples. Although this test cannot be used to make a diagnosis, its effectiveness has been acknowledged in spite of its low positive predictive value $(100 \%$ sensitivity and $92.1 \%$ specificity).${ }^{18}$ The SATAQ-3 was selected because it is the most specific questionnaire available to measure MM influence, since there is no other gold standard related to this variable. For instance, the Questionnaire of Influences on Body Shape Model (Cuestionario de influencia de los modelos estéticos corporales, CIMEC-26) measures related aspects, but does not directly estimate the influence of different media.

As a result of what has been described here, MM have a big influence on adolescent girls and, in turn, it has been demonstrated that adolescent girls who are more influenced by MM had a greater risk of developing an ED. Such risk may be remarkably reduced if MM refrained from conveying extreme thinness models and showed standard models. This way, adolescent girls would not feel pressured by their environment and would stop using the wrong models as reference, and this would prevent the creation of the ideal of a "perfect body".

No specific interventions on models conveyed by MM have been identified, and regulating them is problematic in democratic settings; therefore, MM may implement messages in their shows (e.g., reality-competition programs) ${ }^{15}$ similar to deterrent messages used in relation to smoking control, ${ }^{31}$ although, in this case, they should focus on EDs.

We believe that this study has certain limitations. This was a cross-sectional study, so it allows to establish an association, but not a causeand-effect relationship. Besides, a high percentage of rejection (51\%) was observed in one of the public schools. This school showed a lower prevalence of risk of developing an ED and a lower score in the EAT-26. We suspect that a selection bias was present in this school in relation to positive cases, so the frequency of the risk of developing an ED may have been higher than what has been reported. In addition, participating schools are not representative of students from Lima, so it is not possible to extrapolate prevalence values observed here to other schools. Future studies with probabilistic sampling designs may provide estimations on the risk of developing an ED across the city.

Finally, it is necessary to assess the implementation of promotion and prevention campaigns that convey messages on healthy lifestyles and that serve as guidance for adolescents that may be at risk of developing an eating disorder. It is also important to advise certain television shows to offer a space to convey appropriate messages on how to lose weight in a healthy manner with an adequate diet and exercise, or to encourage MM to show individuals with real shapes instead of inadequate body shape models.

To date, no healthy habits promotion strategy has been implemented in Peru to help counteract the messages conveyed by MM. It would be important to adopt strategies such as the "Eating disorder prevention. The first two-stage prevention program". This strategy started as a research pilot conducted in Spain. It proposes that a team should work in different places where adolescents usually hang out (the main locations would be schools). This strategy works both with parents and adolescents, and therefore provides the necessary knowledge on eating disorders and allows to easily identify early signs and symptoms. ${ }^{33}$

\section{CONCLUSION}

In this study, we observed that the greater the influence of $\mathrm{MM}$, the greater the risk of developing an ED in a sample of female students from Lima, Peru.

\section{REFERENCES}

1. Peláez Fernández M, Labrador Encinas F, Raich Escursell R. Prevalencia de los trastornos de la conducta alimentaria: consideraciones metodológicas. Int J Psychol Physiol Ther 2005;5(2):135-48.

2. Powers P, Santana C. Eating disorders: a guide for the primary care physician. Prim Care 2002;29(1):81-98.

3. Perú. Ministerio de Salud. En los últimos 10 años el número de casos aumentó 10 veces. Recuperación depende del diagnóstico temprano de la enfermedad. Lima: MINSA; 2009. [Accessed on: February 10,2015]. Available at: http:/ / www.minsa.gob.pe/portada/prensa/nota_completa. asp?nota $=7484$.

4. Martínez P, Zusman L, Hartley J, Morote R, Calderón A. Estudio epidemiológico de los trastornos alimentarios $\mathrm{y}$ factores asociados en Lima Metropolitana. Rev Psicol (Lima) 2003;21(2):234-69.

5. Walsh JM, Wheat ME, Freund K. Detection, evaluation and treatment of eating disorders the role of the primary care physician. J Gen Intern Med 2000;15(8):577-90.

6. Mitchison D, Hay PJ. The epidemiology of eating disorders: genetic, environmental, and societal factors. Clin Epidemiol 2014;6:89-97. 
7. Pinheiro AP, Giugliani ER. Body dissatisfaction in Brazilian schoolchildren: prevalence and associated factors. Rev Saude Publica 2006;40(3):489-96.

8. Marín BV.Trastornos dela conducta alimentaria en escolares y adolescentes. Rev Chile Nutr 2002;29(2):86-91.

9. Merino Madrid H, Pombo MG, Godás Otero A. Evaluación de las actitudes alimentarias y la satisfacción corporal en una muestra de adolescentes. Psicothema 2001;13(4):539-45.

10. Stice E, Schupak-Neuberg E, Shaw HE, Stein RI. Relation of media exposure to eating disorder symptomatology: An examination of mediating mechanisms. J Abnorm Psychol 1994;103(4):836-40.

11. Guerro-Prado D, Barjau RomeroJM, Chinchilla Moreno A. Epidemiología de los trastornos de la conducta alimentaria e influencia mediática: una revisión de la literatura. Actas Esp Psiquiatr 2001;29(6):403-10.

12. Derenne JL, Beresin EV. Body image, media, and eating disorders. Acad Psychiatr 2006;30(3):257-61.

13. Salinas Ressini D. Los medios de comunicación, los ideales de belleza y la manifestación de anorexia. Punto Cero 2011;16(23):18-24.

14. MunschS. Study protocol:psychological and physiological consequences of exposure to mass media in young women - an experimental cross sectional and longitudinal study and the role of moderators. BMC Psychol 2014;2:37.

15. Signorini D. Sample size for Poisson regression. Biometrika 1991;78(2):446-50.

16. Lazo Y, Quenaya A, Mayta-Tristán P. Visualización de realities de competencia y riesgo de padecer trastornos de la conducta alimentaria en escolares. Rev Chil Pediatr 2015;86(1):66-7.

17. Garner DM, Olmsted MP, Bohr Y, Garfinkel PE. The eating attitudes test: psychometric features and clinical correlates. Physiol Med 1982;12(4):871-8.

18. Constaín GA, Ricardo RamírezC, Rodríguez-Gázquez ML, Álvarez Gómez M, et al. Validez y utilidad diagnóstica de la escala EAT-26 para la evaluación del riesgo de trastornos de la conducta alimentaria en población femenina de Medellín, Colombia. Aten Primaria 2014;46(6):283-9.

19. Thompson K, Van den Berg P, Roehrig M, Guarda AS, Heinberg LJ. The Sociocultural Attitudes Towards Appearance Scale-3 (SATAQ-3): Development and validation. Int J Eat Disord 2004;35(3):293-304.

20. LlorenteE, Warren CS, de Eulate LP, Gleaves DH.ASpanish version of the Sociocultural Attitudes towards Appearance Questionnaire-3 (SATAQ-3): translation and psychometric evaluation. J Clin Psychol 2013;69(3):240-51.

21. Tiggemann M,Pickering AS. Role of television in adolescent women's body dissatisfaction and drive for thinness. Int J Eat Disord 1996;20(2):199-203.

22. Cusumano DL, Thompson JK. Media influence and body image in 8-11-year-old boys and girls: a preliminary report on the multidimensional media influence scale. Int J Eat Disord 2001;29(1):37-44.

23. Field AE, Camargo CA, Taylor CB, Berkey CS, Colditz GA. Relation of peer and media influences to the development of purging behaviors among preadolescent and adolescent girls. Arch Pediatr Adolesc Med 1999;153(11):1184-9.

24. Facchini M. La preocupación por el peso y la figura corporal en las niñas y adolescente actuales: ¿de dónde proviene? Arch Angent Pediatr 2006;104(4):345-50.

25. Saucedo-Molina T, Unikel Santoncini C. Conductas alimentarias de riesgo, interiorización del ideal estético de delgadez e índice de masa corporal en estudiantes hidalguenses de preparatoria y licenciatura de una institución privada. Salud Ment 2010;33(1):11-9.

26. Souza-Kaneshima A, França AA, Kneube D, Kaneshima EN. Ocorrência de anorexia nervosa e distúrbio de imagen corporal emestudantes do ensinomédio de umaescola da rede pública da cidade de Maringá, Estado do Paraná. Acta Sci Health Sci 2006;28(2):119-27.

27. Meier P, Gray J. Facebook photo activity associated with body image disturbance in adolescent girls. Cyberpsychol Behav Soc Netw 2014;17(4):199-206.

28. Soh NL, Touyz S, Dobbins TA, Surgenor LJ, et al. Restraint and eating concern in North European and East Asian women with and without eating disorders in Australia and Singapore. Aust N Z J Psychiatry 2007;41(6):536-45.

29. UnikelC, Saucedo-Molina T, Villatoro J, Fleiz C. Conductas alimentarias de riesgo y distribución de índice masa corporal en estudiantes de 13 a 18 años. Salud Mental 2002;25(2):49-57.

30. Avila-Funes JA, Gutiérrez-Robledo LM, Ponce de León Rosales S. Validity of height and weight self-report in Mexican adults: results from the national health and aging study. J Nutr Health Aging 2004;8(5):355-61.

31. Crockett L, ShulembergJ, Petersen A. Congruence between objective and self-report data in a sample of young adolescents. J Adolesc Res 1987;2(4):383-92.

32. Wang AL, Ruparel K, Loughead JW, Strasser AA, et al. Content matters: neuroimaging investigation of the brain and behavioral impact of televised anti-tobacco public service announcements. J Neurosci 2013;33(17):7420-7.

33. Casado Morales M, Helguera Fuentes M. Prevención de trastornos de alimentación. Un primer programa de prevención en dos fases. Clínica y Salud 2008;19(1):5-26. 